\title{
PRÁTICAS DE SENSIBILIZAÇÃO AMBIENTAL NA FORMAÇÃO DO PEDAGOGO: UM RELATO DE EXPERIÊNCIA
}

\section{ENVIRONMENTAL AWARENESS PRACTICES IN PEDAGOGUE'S TRAINING: AN EXPERIENCE REPORT}

Fabrícia Souza da Silva ${ }^{1}$

ORCID iD: $\underline{0000-0002-9310-4903}$

Lindalva Sâmela Jacaúna de Oliveira ${ }^{2}$

DORCID iD: 0000-0001-6667-5164

Augusto Fachín Terán ${ }^{3}$

ORCID iD: 0000-0001-9568-7578

Ailton Cavalcante Machado 4

DORCID iD: 0000-0001-6430-1214

\section{RESUMO}

Esta pesquisa aborda uma experiência durante o curso de Educação Ambiental, disciplina oferecida pelo curso de graduação em Pedagogia, da Universidade do Estado do Amazonas (UEA). Os objetivos foram analisar em que medida as práticas de sensibilização ambiental propostas contribuíram para a formação profissional dos acadêmicos em relação às problemáticas socioambientais na sociedade contemporânea e identificar se o contato dos discentes com o meio natural despertou a formação de um sujeito mais sensível ambientalmente. O estudo foi realizado por meio de uma abordagem qualitativa, tendo como participantes 60 alunos do $5^{\circ}$ período e o professor da disciplina. As técnicas utilizadas na coleta de dados foram a observação participante e a entrevista estruturada. O embasamento teórico está fundamentado em Brasil (1988, 1999, 2002, 2012), Alencar e Barbosa (2018), Tristão (2008), Maturana (1998), entre outros. De acordo com os resultados alcançados, as práticas de sensibilização ambiental realizadas, mostram um efeito positivo na formação do pedagogo, os quais adquiriram conhecimentos acerca das práticas e valores ambientais, tais como: responsabilidade individual, cooperação e cuidados com o meio natural. Portanto, por meio das ações e práticas de educação ambiental é possível incentivar esses indivíduos a pensar coletivamente e não apenas como indivíduos, entendendo as questões presentes no cotidiano de maneira contextualizada e crítica.

\footnotetext{
${ }^{1}$ Graduada em Pedagogia, Mestranda do Programa de Pós-Graduação em Educação e Ensino de Ciências na Amazônia, da Universidade do Estado do Amazonas (UEA), Manaus, Amazonas, Brasil. Endereço para correspondência: Rua 2, Quadra 21, casa 103, Nova Cidade, Manaus, Amazonas, Brasil, CEP: 69.092.648. Email: fabriciasilva.mestrado@gmail.com.

${ }^{2}$ Graduada em Pedagogia, Mestranda do Programa de Pós-Graduação em Educação e Ensino de Ciências na Amazônia, da Universidade do Estado do Amazonas (UEA), Manaus, Amazonas, Brasil. Endereço para correspondência: Rua Otávio Cabral, casa 27, Petrópolis, Manaus, Amazonas, Brasil, CEP: 69067-370. E-mail: lindalva1802@gmail.com.

${ }^{3}$ Doutor em Ecologia. Instituto Nacional de Pesquisas da Amazônia (INPA). Professor do Curso de Pedagogia e do Programa de Pós-Graduação em Educação e Ensino de Ciências na Amazônia, da Universidade do Estado do Amazonas (UEA), Manaus, Amazonas, Brasil. Endereço para correspondência: Avenida Djalma Batista, 2470, Chapada, Manaus, Amazonas, Brasil, CEP: 69050-010. E-mail: fachinteran@ yahoo.com.br.

${ }^{4}$ Graduado em Pedagogia, Mestrando do Programa de Pós-Graduação em Educação e Ensino de Ciências na Amazônia, da Universidade do Estado do Amazonas (UEA), Manaus, Amazonas, Brasil. Endereço para correspondência: Rua São Carlos, casa 12, Quadra P, Condomínio Manoel Nogueira, Alvorada, Manaus, Amazonas, Brasil, CEP: 69.042.224. E-mail: ailtoncavalcante@yahoo.com.br.
} 
Palavras-chave: Educação Ambiental. Sensibilização Ambiental. Formação do Pedagogo.

\begin{abstract}
This research addresses an experience during the Environmental Education course, a discipline offered by the undergraduate course in Pedagogy of Amazonas State University (UEA). The objectives were to analyze the extent of environmental awareness practices their contribution to the professional training of academics according to the socio-environmental problems in contemporary society, also to identify whether the contact of students with the natural environment has aroused the formation of a more environmentally sensitive subject. This is a qualitative study, and sixty (60) fifth graders and the professor of the discipline participated in this research. The data was collected with participant observation and structured interview. The theoretical basis is grounded on Brazil (1988, 1999, 2002, 2012), Alencar\& Barbosa (2018), Tristão (2008), Maturana (1988), amongst others. According to the achieved results, the environmental awareness practices carried out show a positive effect in the pedagogue's training, whom gathered knowledge about environmental practices and values, such as: individual responsibilities, cooperation and cares regarding the natural environment. Therefore, through environmental education actions and studies, it is possible to encourage such individuals to think collectively and not just as individuals, understanding the issues present in everyday life in a contextualized and critical manner.
\end{abstract}

Keywords: Environmental Education. Environmental Awareness. Pedagogue's training.

\title{
1 INTRODUÇÃO
}

A Educação Ambiental (EA) é um assunto que ao longo dos anos vem ganhando um maior destaque pela necessidade dos seres humanos em reconhecerem a importância de se preservar o meio ambiente, de tal modo, que a escola tornou-se a grande aliada do planeta terra na implementação deste intento. Neste sentido, trabalhar a EA na formação do Pedagogo é fundamental para a formação de professores conscientes ambientalmente, com capacidade em aplicar na sala de aula, as práticas pedagógicas que visam a sensibilização para os problemas socioambientais existentes na sociedade.

O aluno deve ser visto como o sujeito do conhecimento, já que o mesmo representa o agente ativo na apreensão, elaboração e recriação do conhecimento. Assim, cabe ao educador o papel de facilitar este processo. As ações educativas junto à sociedade civil acompanham este paradigma, devendo, também, estar referenciadas no contexto cultural, que abrange as práticas e representações da comunidade, além de incluir os processos de educação formais ali desenvolvidos, à medida que a escola é concebida como espaço da comunidade (ALVES, 1995).

Dentro deste contexto, vemos a EA como um meio de promover a percepção e a compreensão dos fatores que interagem no tempo e no espaço, na vida e nas suas múltiplas perspectivas, permitindo, assim, definir os valores e as motivações que conduzem o ser humano 
aos padrões de comportamento de preservação e à melhoria do tratamento ao meio ambiente e, por conseguinte, a uma melhor qualidade de vida (COSTA; COSTA, 2011).

Neste estudo objetivou-se analisar em que medida as práticas de sensibilização ambiental na disciplina de Educação Ambiental, do Curso de Licenciatura em Pedagogia, da Universidade do Estado do Amazonas (UEA), contribuíram para a formação profissional dos acadêmicos, identificando se o contato dos discentes com o meio natural despertou a formação de um sujeito mais sensível ambientalmente.

\title{
2 REFERENCIAIS TEÓRICOS
}

\subsection{Educação Ambiental no Ensino Superior}

Não poderíamos discutir a EA na formação inicial do pedagogo, sem, antes, olharmos a trajetória e o modo como esta vem sendo inserida no Ensino Superior, no sentido de entender as diversas abordagens praticadas nas Instituições de ensino.

Partindo deste pressuposto, é necessário compreender os princípios, fundamentos e objetivos da EA. Para isto, tomou-se como base a Lei brasileira $\mathrm{N}^{\circ} 9.795$, de 27 de abril de 1999, que em seu Artigo $1^{\circ}$ descreve que a EA é:

\begin{abstract}
O processo em que se busca despertar a preocupação individual e coletiva para as questões ambientais, garantindo o acesso à informação e à linguagem adequadas, contribuindo para o desenvolvimento de uma consciência crítica e estimulando o enfrentamento das questões ambientais e sociais. Desenvolveu-se num contexto de complexidade, procurando trabalhar a mudança cultural, mas também a transformação social, assumindo a crise ambiental como uma questão ética e política (BRASIL, 1999, p.1).
\end{abstract}

Nos dizeres do Decreto No 4.281/2002, que estabeleceu a Política Nacional de Educação Ambiental (PNEA), em seu Artigo $1^{\circ}$, em cujo texto lê-se:

\footnotetext{
Art. $1^{\circ}$ - Entende-se por Educação Ambiental os processos por meio dos quais o indivíduo e a coletividade constroem valores sociais, conhecimentos, habilidades, atitudes e competências voltadas para a conservação do meio ambiente, bem como de uso comum do povo, essencial à sadia qualidade de vida e sua sustentabilidade.
}

Nesta conjuntura, a EA deve promover o desenvolvimento da cidadania, incentivando a participação individual e coletiva, a partir de um olhar ético e crítico da realidade, conscientizando a população humana de que a conservação do meio ambiente é importante para a manutenção dos ecossistemas. 
Em consonância com este pensamento, Maturana (1998, p. 70), descreve que a EA deve promover "[...] a atuação na conservação da natureza e a sua compreensão, a ponto de excluir a ideia de domínio, mas sim, um convívio com responsabilidade pelo individual e coletivo e o distanciamento de qualquer abuso".

No Brasil, a EA ganhou força e passou a ser introduzida nos sistemas educacionais a partir da promulgação da Lei No 6.938 , de agosto de 1981, que estabeleceu a Política Nacional do Meio Ambiente, seus fins e mecanismos de formulação e aplicação, entre outras providências, porém só passou a ser obrigatória a partir da promulgação da Constituição Federal de 1988, a qual destaca em seu Artigo 225, Inciso VI, que “a Educação Ambiental deverá ser promovida em todos os níveis de ensino, com o desígnio de conscientizar os cidadãos para a preservação e a conservação do meio ambiente" (BRASIL, 1988, p.64).

De acordo com a Lei brasileira $\mathrm{N}^{\circ}$ 9.795, de 27 de abril de 1999, regulamentada pelo Decreto $N^{\circ} 4.281$, de 25 de junho de 2002, que estabeleceu a PNEA, o Brasil foi o primeiro país da América Latina a reconhecer, oficialmente, a EA como ferramenta para buscar e atingir padrões mais sustentáveis na sociedade.

Embora a EA não seja uma disciplina presente nos currículos da Educação Básica, o Artigo $2^{\circ}$, da PNEA, enfatiza que a mesma seja um componente essencial e permanente da Educação Nacional, devendo estar presente, de forma articulada, em todos os níveis e modalidades do processo educativo, em caráter formal e não-formal (BRASIL, 2002). Desta forma, a Lei estabelece que a EA não é uma disciplina escolar, mas, sim, um processo permanente, voltado para a vida, no seu sentido mais profundo, vida esta que surge das relações entre os seres que habitam o planeta, constituindo-se em elos de uma mesma cadeia (BRASIL, 1999).

A referida Lei determina, ainda, em seu Artigo $9^{\circ}$, Inciso II, a necessidade de incluir a EA no âmbito dos currículos das Instituições de Ensino, públicas e privadas, de Nível Superior. Neste contexto, é pertinente enfatizar que as diretrizes formuladas pela PNEA (BRASIL, 1999), enfatizam o papel das universidades como um espaço de produção e articulação de saberes, em função das demandas sociais, de forma a legitimar a produção do conhecimento e colocá-lo à disposição da sociedade.

Outro marco legal que permite compreender a trajetória da EA no Ensino Superior são as Diretrizes Nacionais para a Educação Ambiental, Resolução CNE/CP No 2, de junho de 2012, que, em seu Artigo $8^{\circ}$, estabelece que: 
A Educação Ambiental, respeitando a autonomia da dinâmica escolar e acadêmica, deve ser desenvolvida como uma prática educativa integrada e interdisciplinar, contínua e permanente, em todas as fases, etapas, níveis e modalidades, não devendo, como regra, ser implantada como disciplina ou componente curricular específico (BRASIL, 2012, p. 3).

As Diretrizes Nacionais para a EA orientam, ainda, em seu Artigo 12, que a EA tanto nos currículos da Educação Básica, quanto da Educação Superior ocorram por meio da transversalidade, mediante temas relacionados ao meio ambiente e à sustentabilidade socioambiental, como conteúdo dos componentes já constantes do currículo, pela combinação de transversalidade e de tratamento nos componentes curriculares (BRASIL, 2012, p. 3).

Freitas et al. (2006), destaca que a criação de disciplinas voltadas para os aspectos metodológicos da EA nas universidades é facultada, o que tem permitido experiências formativas em algumas Instituições de Ensino Superior (IES). Nesta perspectiva, é importante enfatizar que a EA no Ensino Superior precisa ser desenvolvida a partir da inter-relação da tríade ensino-pesquisa-extensão, uma vez que a função do Ensino Superior não é, somente, preparar o indivíduo para o exercício de uma profissão, mas também prepará-lo para a vida consciente, política e socialmente.

Por tais motivos, Alencar e Barbosa (2018), argumentam que as IES necessitam de um maior empenho e que, entre outros aspectos, incluam a reconstrução por meio da inter e transdisciplinaridade, da inovação tecnológica e do compromisso com a sustentabilidade socioambiental. A contribuição com a dimensão público-universal da educação recai sobre a responsabilidade social dessas instituições.

Ao Ensino Superior e, mais especificamente, aos currículos dos cursos, cabe ainda promover discussões e ações que sinalizem para a ética ambiental das atividades profissionais e que, ao mesmo tempo, busquem soluções para os problemas ambientais em caráter global. Assim sendo, o Ensino Superior, bem como o Ensino Básico, devem configurar-se como um lócus privilegiado para a implementação da EA, visando a construção de uma nova sociedade, capaz de promover mudanças e comportamentos significativos, no que concerne aos problemas ambientais que enfrentamos, atualmente.

Para Alencar e Barbosa (2018), o momento histórico almeja um processo de sensibilização e conscientização da comunidade acadêmica sobre a importância da sustentabilidade ambiental. Neste sentido, acreditamos que a EA é essencial nesta modalidade de ensino, tendo em vista que através da mesma podemos formar indivíduos mais conscientes ambientalmente, capazes de mudar a realidade, na qual estão inseridos, bem como disseminar, para as futuras gerações, os conhecimentos adquiridos. 


\title{
2.2 Sensibilização ambiental na formação inicial do Pedagogo
}

A Educação Ambiental deve estar presente em todos os momentos da vida do ser humano, pois desde a mais tenra infância a criança precisa reconhecer-se como um ser integrante do meio em que vive. Pensando nisto, é que a formação do pedagogo torna-se crucial neste processo, já que sua área de atuação dá-se nos anos iniciais da vida escolar das crianças.

Segundo a Resolução CNE/CP No 2, de $1^{\circ}$ de julho de 2015, que institui as Diretrizes Curriculares Nacionais para o Curso de Graduação em Pedagogia em seu Artigo $2^{\circ}$, determina que:

\begin{abstract}
Art. $2^{\circ}$ - As Diretrizes Curriculares Nacionais para a Formação Inicial e Continuada, em Nível Superior, de Profissionais do Magistério para a Educação Básica, aplicamse à formação de professores para o exercício da docência na Educação Infantil, no Ensino Fundamental, no Ensino Médio e nas respectivas modalidades de educação (Educação de Jovens e Adultos, Educação Especial, Educação Profissional e Tecnológica, Educação do Campo, Educação Escolar Indígena, Educação à Distância e Educação Escolar Quilombola), nas diferentes áreas do conhecimento e com integração entre elas, podendo abranger um campo específico e/ou interdisciplinar. $\S 1^{\circ}$ - Compreende-se a docência como uma ação educativa e como um processo pedagógico intencional e metódico, envolvendo conhecimentos específicos, interdisciplinares e pedagógicos, conceitos, princípios e objetivos da formação que se desenvolvem na construção e apropriação dos valores éticos, linguísticos, estéticos e políticos do conhecimento, inerentes à sólida formação científica e cultural do ensinar/aprender, à socialização e à construção de conhecimentos e sua inovação, em diálogo constante entre diferentes visões de mundo.
\end{abstract}

Deste modo, as Diretrizes Curriculares deste curso, evidenciam a abrangência da Pedagogia nos diferentes níveis de ensino, estando presente nos diferentes campos do saber, e a EA compõe a lista de aplicações do curso, na medida em que desenvolve os valores éticos e políticos da vida em sociedade. É por isso que a EA deve ser enfatizada na formação profissional dos futuros pedagogos de forma a capacitá-los a desenvolver ações no ambiente de trabalho, quando exercerem, realmente, suas funções como tal.

Contudo, faz-se necessária a reflexão de como vêm ocorrendo esta formação nas Universidades, de tal modo que, esta formação possa surtir um efeito positivo no desenvolvimento da sensibilização ambiental no âmbito escolar. Por isso, é fundamental conhecer o processo de construção do ser professor na integração de seres humanos conscientes e sensibilizados com as problématicas ambientais que atingem a sociedade.

Pensando nisso, a articulação das ações da disciplina de Educação Ambiental, ainda na graduação, precisa proporcionar aos acadêmicos esta sensibilização ambiental, afim de gerar reflexões e mudança de atitude, entre outras transformações pessoais, fazendo-os entender que 
cada ser vivo necessita do outro para sua sobrevivência, elo este que todos os seres humanos necessitam compreender para, assim, tornar possível as transformações do meio ambiente, onde a vida possa ser valorizada por todos. Por isso, o curso de pedagogia no processo de sua organização curricular busca inserir as questões ambientais, no intuito de debater as mudanças que ocorrem no meio ambiente, pois, ao formar cidadãos, cujo papel é ser responsável pela educação inicial das crianças, há a necessidade de mudanças conceituais em relação ao meio ambiente.

Manzano (2003, p. 10) ressalta as carências existentes na formação do pedagogo, a respeito dos conteúdos, como também fala sobre as novas perspectivas metodológicas de trabalhar a Educação Ambiental.

[...] os professores das séries iniciais do Ensino Fundamental têm apresentado uma formação, em geral, deficiente em conteúdos específicos. Apesar de sua dedicação, estes profissionais carecem de estudos sobre a presença de atividades, projetos e ações sobre o tema meio ambiente em suas práticas, bem como sobre a origem das informações utilizadas por esses professores em sua atividade docente.

Thomaz (2006), salienta que na formação inicial do pedagogo, a sensibilização ambiental é considerada de extrema relevância, uma vez que é necessário despertar nos futuros professores a sensibilidade para lidar com os diversos problemas socioambientais, presentes na realidade dos alunos. É por isso que, em sala de aula, torna-se essencial o trabalho de estimular a curiosidade e os sentimentos de pertencimento que os indivíduos necessitam despertar dentro de si, para, assim, construir uma socidade sensibilizada e consciente da gravidade das problemáticas em torno do meio ambiente.

Deste modo, no curso da formação dos pedagogos, a disciplina referente ao meio ambiente deve envolver práticas que os impulssionem a pensar e a reaproximá-los dos recursos naturais, fazendo-os entender que a mundança precisa ocorrer, primeiro, no educador e, posteriormente, noseducandos e, assim, possam ser, ambos, ecologicamente educados.

Para Silva, Santos e Fachín-Terán (2019) a sensibilização ambiental é considerada uma importante ferramenta da EA para despertar nos alunos o interesse pela natureza, possibilitando a formação de um elo mais sensível entre homem e meio ambiente. Assim, destacamos a importância das práticas de sensibilização na formação de professores. 


\section{METODOLOGIA}

A pesquisa apresenta uma abordagem qualitativa. Para Minayo (2003, p. 30) a referida abordagem "aprofunda-se no mundo dos significados das ações e relações humanas, um lado não perceptível e não captável em equações, médias e estatísticas”.

Os sujeitos participantes foram 60 alunos e um professor, de duas turmas do $5^{\circ}$ período, do curso de Licenciatura em Pedagogia, da Escola Normal Superior (ENS), da Universidade do Estado do Amazonas (UEA), matriculados nos turnos matutino e vespertino, na disciplina de Educação Ambiental.

No que se refere às técnicas para a coleta de dados, Bauer e Gaskell (2015), destacam que na pesquisa qualitativa existem diversos meios de coleta de dados, dentre os quais citam a observação participante e a entrevista, bem como o uso de textos, desenhos, imagens e sons. Os dados obtidos, a partir destas técnicas, foram organizados para construir o corpus da pesquisa, que será a base para a construção dos resultados. Assim, os dados foram obtidos através da observação participante e entrevistas feitas com os alunos. A observação foi realizada no período de agosto a dezembro de 2018, seguindo um roteiro pré-estabelecido.

Inicialmente, foram feitas observações das aulas teóricas, ministradas pelo docente, afim de averiguar quais conteúdos eram abordados pelo professor e quais metodologias ele utilizava. Neste contexto, podemos descrever que o professor buscou apresentar para os alunos o que era a Educação Ambiental, enfatizando sua perspectiva transversal nos Parâmetros Curriculares Nacionais (PCN's), assim como discorreu sobre temas socioambientais relevantes na atualidade, tais como a poluição do solo, ar e água, o desmatamento, as queimadas, o tráfico de animais, a fome no planeta e o descarte de materiais poluentes, tais como o plástico, o papel, o vidro e os metais, dentre outros.

Um aspecto relevante que podemos salientar é que o docente procurou ensinar para os futuros pedagogos como desenvolver essas temáticas não somente na Educação Infantil, como também nos anos iniciais do Ensino Fundamental, tendo em vista que o licenciado em pedagogia recebe habilitação para lecionar nestas duas etapas de ensino. Em relação às metodologias utilizadas, podemos citar a projeção de vídeos educativos, a leitura de textos informativos, as aulas expositivas dialogadas e as práticas de campo, nas quais os alunos puderam visitar espaços de aprendizagem não-formais da cidade de Manaus, entre os quais o Bosque da Ciência, do Instituto Nacional de Pesquisas da Amazônia (INPA), e o Corredor Ecológico Urbano do Igarapé do Mindu (CEUM). 
O foco deste estudo foi o projeto "Melhorando o ambiente da Escola Normal Superior (ENS/UEA)", realizado como uma atividade prática de sensibilização ambiental na disciplina de EA. As atividades do projeto foram realizadas na área externa da unidade de ensino. Para isto, o professor dividiu as turmas em cinco grupos e para cada um destes o docente sinalizou uma ilha (Figura 1), que são canteiros de cimento em formato circular, localizados no estacionamento da referida universidade.

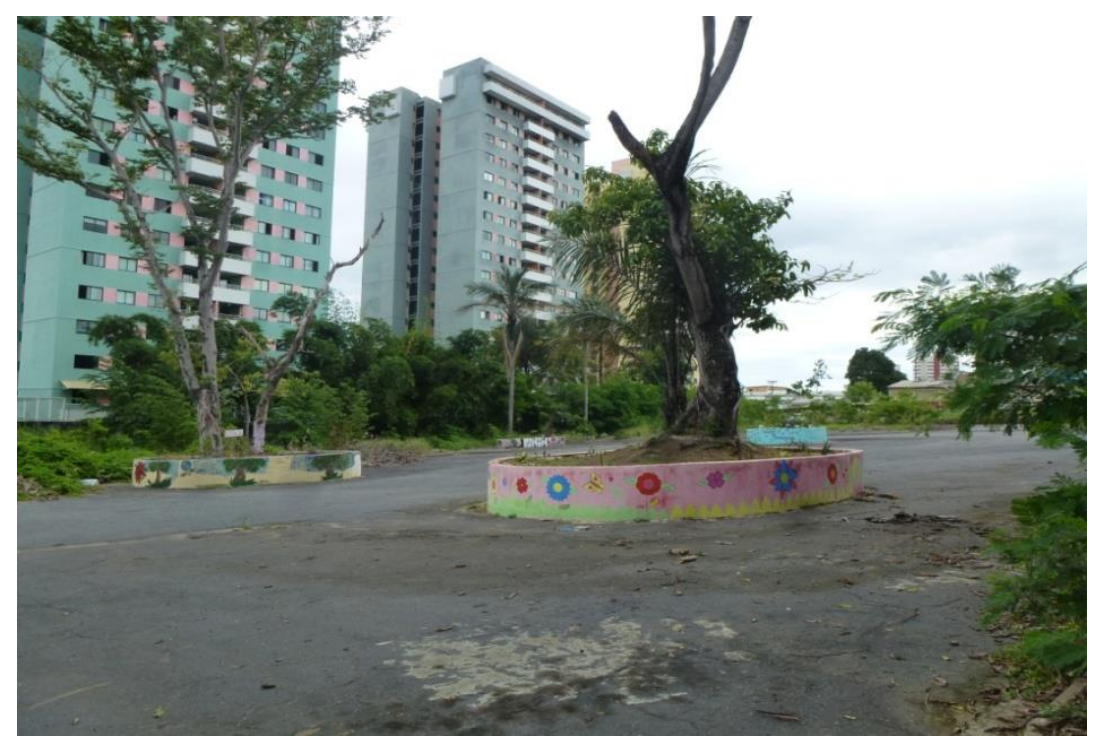

Figura 1-Ilhas no pátio do estacionamento.

Fonte - Figura selecionada pelos pesquisadores, a partir da coleta de dados (2018).

Após a formação dos grupos, os estudantes fizeram um mapeamento das ilhas para definir o plano de trabalho que seria executado durante cinco meses, que, posteriormente, foi divido da seguinte forma:

a) Preparação do solo para o plantio: nesta etapa, as equipes fizeram uma limpeza no ambiente, retirando matos, pedaços de galhos secos e plantas invasoras. Após este processo inicial, foi feita a irrigação do solo e a inserção de adubo;

b) Plantio das mudas: Os alunos selecionaram mudas de plantas que são resistentes à altas temperaturas, tendo em vista que a atividade foi feita no período do verão amazônico, cuja temperatura chega a quase 40 graus. Dentre as plantas selecionadas podemos citar o Cacto (Cactaceae), a Onze Horas (Portulaca grandiflora) e a Espada de São Jorge (Sansevieria trifasciata);

c) Pintura: após fazerem os procedimentos descritos acima, os discentes realizaram a pintura da parte externa das ilhas, escolhendo cores e desenhos que representassem a identidade de cada grupo. Alguns alunos também colocaram pequenos objetos de decoração na parte 
interna, deixando o ambiente mais criativo e colorido;

d) Monitoramento diário: todos os dias as equipes faziam a irrigação do solo e analisavam o crescimento das plantas, para verificar se as mesmas estavam adaptando-se bem ao solo. Além disso, faziam a contenção de algumas pragas agrícolas que ameaçavam o crescimento das plantas, como, por exemplo, as formigas cortadeiras.

Ao final das atividades do projeto, realizamos a aplicação de um questionário e uma entrevista com os alunos, a fim de analisar em que medida a prática de sensibilização ambiental, proposta na disciplina, contribuiu para a formação profissional, pessoal e social dos futuros pedagogos, tendo em vista que tais conhecimentos, adquiridos durante esta formação, poderão ser aplicados em sala de aula, assim como também buscamos identificar se este contato dos discentes com o meio natural despertou neles a formação de um sujeito mais sensível ambientalmente.

No que se refere ao tratamento e análise dos dados, utilizamos a análise de conteúdo de Bardin, segundo os passos determinados pela autora, como pré-análise, exploração do material e tratamento e interpretação dos resultados (BARDIN, 2016).

Na pré-análise fizemos a leitura flutuante do material, no intuito de selecionar os dados que iriam compor o corpus da pesquisa, como as entrevistas e fotos. Em seguida, partimos para a exploração do material, objetivando categorizar as informações obtidas através da seleção semântica. Por fim, foi feita a interpretação dos dados para dar significado ao material coletado.

\section{RESULTADOS E DISCUSSÃO}

\subsection{A importância das práticas de sensibilização ambiental no curso de pedagogia: o que dizem os pedagogos em formação?}

O processo que envolve a formação do educador no âmbito da EA é bastante complexo, visto que suas concepções acerca do meio ambiente e da própria EA já se encontram estabelecidas, fazendo parte da personalidade dos acadêmicos. Por isso, faz-se necessário a implementação de práticas que possam fazê-los pensar e refletir sobre o seu papel como cidadãos participantes de uma sociedade, mas também como futuros educadores. De acordo com Tristão (2008, p. 187):

[...] a universidade ganha uma importância fundamental na formação ambiental, pois revela-se como lócus não só do saber científico, mas também na formação de novos cientistas e professores/as, produzindo sentido nas práticas educativas e exercendo a 
influência sobre a EA. Se temos de alcançar um futuro sustentável, esses contextos adquirem um papel importante nas redes de conhecimentos, na formação de comportamentos e valores sociais e ambientalmente sustentáveis.

Pensar na EA é realizar a reflexão a respeito da possibilidade de mudança de comportamento, bem como da valorização do meio ambiente, começando pelas espécies ameaçadas de extinção, como também analisar as questões que envolvem queimadas e a poluição das águas, dentre outras, que fazem parte do cotidiano. A contextualização com a realidade pela qual o acadêmico está inserido, também, precisa estar presente na sala de aula, para que o mesmo possa fazer esta relação com suas experiências de vida.

Nesta perspectiva, o objetivo dos questionamentos foi conhecer o sentimento dos acadêmicos, fossem estes positivos ou negativos, procurando destacar as novas atitudes adquiridas durante as aulas. Nesta pesquisa, destaca-se, também, a importância dada em trabalhar a EA de forma ativa, dentro de sala de aula. No quadro 1, é possível verificar as respostas dos acadêmicos, bem como algumas das transformações de pensamento dos mesmos.

\begin{tabular}{|l|l|}
\hline & $\begin{array}{l}\text { Questionamento: Quais suas experiências e mudanças de comportamento/atitude experimentada } \\
\text { por você, como consequência de seu aprendizado, durante o trabalho realizado nas ilhas? }\end{array}$ \\
\hline 01 & $\begin{array}{l}\text { Eu achava que ter plantas em casa só trazia sujeira e mais trabalhos. Após o trabalho já estou } \\
\text { fazendo um mini jardim no pátio da minha casa, pois além de ter aprendido a gostar de cuidar, } \\
\text { acho linda. }\end{array}$ \\
\hline 02 & $\begin{array}{l}\text { Inicialmente, eu não sabia como cuidar de plantas, até mencionei em uma das aulas que tudo } \\
\text { que eu plantava morria e após começar a pesquisar e trabalhar nas ilhas, eu me motivei a plantar } \\
\text { em minha casa também, e faz pelo menos dois ou três meses que eu mantenho viva uma bela } \\
\text { roseira, que recentemente desabrochou, e um cacto bem verdinho, que tem crescido bastante. }\end{array}$ \\
\hline 03 & $\begin{array}{l}\text { Uma mudança de comportamento que percebo que ocorreu comigo, foi a dedicação e paciência, } \\
\text { pois tive que me dedicar para que a mudança na ilha ocorresse. }\end{array}$ \\
\hline
\end{tabular}

Quadro 1 - Respostas dos estudantes sobre as experiências vivenciadas por eles.

Fonte - Elaborado pelos autores (2018).

Após a leitura dos depoimentos apresentados no quadro acima, é perceptível a influência que as práticas nas aulas de EA tiveram na concepção dos estudantes, as quais desencadearam ações e atitudes que favoreceram o elo que o indivíduo possui com a natureza, bem como a mudança de olhar diante de uma planta que antes era vista como algo que apenas "dá trabalho" para um ser vivo que tem uma função primordial no meio ambiente, mas que necessita de cuidados para desenvolver-se. 
Desta forma, podemos verificar que a inserção de práticas vinculadas à EA, na graduação, estimula a conexão dos fundamentos teóricos com a prática, estabelecendo uma relação concreta do que pode ser realizado dentro do âmbito profissional. Por isso, conhecer as concepções dos acadêmicos do curso de pedagogia sobre as atividades realizadas, na disciplina de EA, foi de fundamental importância para analisarmos como vem sendo desenvolvida esta formação e se tais ações pedagógicas estão sendo capazes de sensibilizá-los e, assim, enriquecer, mais ainda, sua formação profissional, no que se refere às questões ambientais mundiais.

No quadro 2, destacamos a reflexão sobre esta sensibilização ambiental.

\begin{tabular}{|l|l|}
\hline & $\begin{array}{l}\text { Questionamento: Você acredita que houve uma sensibilização ambiental após o trabalho } \\
\text { realizado na ilha? Justifique. }\end{array}$ \\
\hline 01 & $\begin{array}{l}\text { Sim, pois comecei a enxergar o meio ambiente com outros olhos e me preocupar com cada } \\
\text { atitude minha sobre o meio ambiente, digamos que minhas atitudes não eram tão erradas, mas a } \\
\text { partir do trabalho realizado nas ilhas meu olhar mudou mais ainda. }\end{array}$ \\
\hline 02 & $\begin{array}{l}\text { Sim, com este trabalho despertei para quando propuser para meus alunos um trabalho dessa } \\
\text { proporção, e me certificar de que eu contribuí com pelo menos a parte teórica. }\end{array}$ \\
\hline 03 & $\begin{array}{l}\text { Sim, pois passei a refletir sobre questões referentes ao meio ambiente, limpeza do local e } \\
\text { preservação ambiental. }\end{array}$ \\
\hline 04 & $\begin{array}{l}\text { Sim, pois antes desta sensibilização não costumava me importar muito, até mesmo com as } \\
\text { plantas de casa, após isso, procuro cuidar, regar e adubar sempre que necessário. }\end{array}$ \\
\hline 05 & $\begin{array}{l}\text { Penso que sim, todo o meu grupo passou a trabalhar com um maior cuidado com as plantinhas, } \\
\text { à medida que fomos tendo retorno, ver um brotinho nascer ou uma nova folhinha nascer nos } \\
\text { empolgava e nos dava satisfação. }\end{array}$ \\
\hline
\end{tabular}

Quadro 2 - Respostas dos estudantes às questões relacionadas com a sensibilização ambiental. Fonte - Elaborado pelos autores (2018).

Considerando as respostas dos acadêmicos acima relatadas, pode-se considerar que o uso efetivo de ações práticas na graduação, favorece o despertar da sensibilização pela maioria dos que participaram, ativamente, de todo o processo de melhoramento das ilhas, e concomitante a isso, os acadêmicos conseguiram entender o papel fundamental do educador na vida do estudante da Educação Básica. Peres et al. (2018), destaca que "a Educação Ambiental está presente no currículo escolar do Ensino Fundamental, mas é visível que a conscientização ainda não está firmada", por isso, trabalhar a sensibilização na graduação é imprescindível para estabelecer uma conexão entre a EA com a realidade do estudante.

Para avaliarmos se houve, efetivamente, uma inter-relação entre a teoria e a prática,

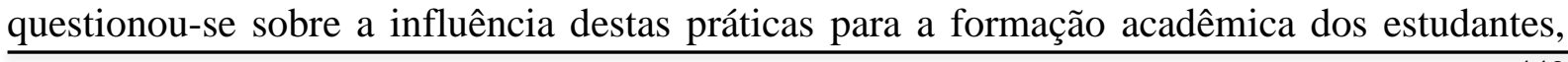


quais ações foram consideradas durante todo o processo de execução das práticas e se foi estabelecido uma troca de conhecimento, no decorrer das mesmas.

\begin{tabular}{|l|l|}
\hline & $\begin{array}{l}\text { Questionamento: Quais as contribuições que o trabalho realizado na ilha trouxe para sua } \\
\text { formação acadêmica sobre a Educação Ambiental? }\end{array}$ \\
\hline 01 & $\begin{array}{l}\text { Trouxe uma concepção muito mais ampla sobre o contato com o meio natural, não apenas na } \\
\text { teoria, mas na prática. E esse contato direto promoveu uma relação entre o estudante e o meio } \\
\text { natural, despertando uma sensibilização no acadêmico, que de fato será transmitido lá na frente }\end{array}$ \\
\hline 02 & $\begin{array}{l}\text { Entendimento acerca do solo, tipos de plantas, principalmente as mais resistentes como os } \\
\text { cactos. A importância de um espaço como aquele para a universidade, bem como a importância } \\
\text { da natureza em meio à vida urbana. }\end{array}$ \\
\hline 03 & $\begin{array}{l}\text { A disciplina de Educação Ambiental em conjunto com o trabalho nas ilhas, me possibilitou } \\
\text { compreender mais a natureza, o meio ambiente, e me levaram a refletir sobre o meu papel de } \\
\text { repassar aos meus futuros alunos essa sensibilização e cuidado com o ambiente no qual vivemos. }\end{array}$ \\
\hline 04 & $\begin{array}{l}\text { Este trabalho me fez compreender como é importante ter algum objeto para se trabalhar a } \\
\text { Educação Ambiental (ilha) de forma prática. }\end{array}$ \\
\hline 05 & $\begin{array}{l}\text { As contribuições foram as seguintes: Uma percepção ambiental bem melhor, uma sensibilização } \\
\text { com a natureza que precisa ser cuidada e preservada. Em casa, fizemos até um pequeno jardim } \\
\text { por conta da ilha. }\end{array}$ \\
\hline
\end{tabular}

Quadro 3 - Respostas relacionadas às contribuições do trabalho realizado nas ilhas para a formação acadêmica dos alunos.

Fonte - Elaborado pelos autores (2018).

Podemos afirmar diante destas repostas que houve, realmente, durante a referida prática, uma intensa troca de conhecimentos, e que os acadêmicos compreenderam que a teoria e a prática são indissociáveis e que, portanto, ambas precisam ser trabalhadas juntas, assim como foi realizado na disciplina.

A reflexão por parte dos acadêmicos demonstra que a disciplina é muito mais efetiva, quando executa ações que os façam ter atitudes, noções de ambiente, conhecimentos sobre os vegetais, desde os mais resistente aos mais fracos, levando-se em conta o clima quente da cidade de Manaus, desenvolvendo um olhar pedagógico no espaço em que se trabalha, assim como foi feito no espaço da ilha, utilizado para trabalhar inúmeros fatores presentes nas questões ambientais.

O trabalho realizado na disciplina estudada levou os estudantes a refletirem que o meio ambiente faz parte do seu dia a dia e que, por isso, suas atitudes de antes foram vistas por eles como "erradas" e que influenciaram, diretamente, na sua realidade. É, desta forma, que a EA 
busca fazer estas reflexões junto aos cidadãos, levando em consideração o papel dos acadêmicos, como futuros docentes de uma sala de aula, na qual encontram-se indivíduos ainda em processo de formação de personalidade e de visão de mundo.

\section{CONSIDERAÇÕES}

O processo de formação profissional do pedagogo é complexo e demanda a estruturação de metodologias didáticas que forneçam aprendizado e experiência a serem ressignificadas e utilizadas no momento da prática em sala de aula. Todavia, por meio da pesquisa é possível compreender que tal processo, quando realizado envolvendo o contexto ao qual o acadêmico esta inserido, tem um efeito positivo em sua formação.

Nesta perspectiva, os documentos oficiais apresentados durante a disciplina foram as bases para a execução de cada etapa do trabalho no projeto, visto, que todos os assuntos trabalhados eram direcionados ao foco do curso de pedagogia na área ambiental, tanto na Educação Infantil como no Ensino Fundamental.

Por meio das ações desenvolvidas na disciplina, percebeu-se um avanço da sensibilização dos acadêmicos em relação ao meio ambiente, bem como a postura dos mesmos como profissionais da educação. O projeto "Melhorando o ambiente da Escola Normal Superior", proporcionou experiências entre a teoria e a prática, fazendo-os compreender que ambas são indissociáveis no processo de ensino e aprendizagem.

Diante disto, as respostas obtidas pelos estudantes evidenciaram a compreensão das problemáticas ambientais da região amazônica e do mundo, ou seja, que é possível sensibilizar os indivíduos mesmo em idade adulta, bastando, para isto, que haja um contex to com a realidade dos mesmos, fazendo-os refletir sobre os inúmeros impactos ambientais que a natureza sofre todos os dias e que a mundança de comportamento precisa partir do interior para o exterior, possibilitando a transformação do meio ambiente para melhor.

As ações da disciplina foram fundamentais para a formação profissional dos acadêmicos, pois, mostrou que a EA deve estar presente em todas as disciplinas do currículo, de forma transversal, sendo possível transformar o ambiente de uma escola sem natureza, em outro, com plantas, no qual pode-se fazer um trabalho docente de forma interdisciplinar. Verificamos que os acadêmicos internalizaram, além das questões ambientais, a necessidade de olhar para o outro de forma coletiva, além de adquirir a paciência necessária para observar o 
nascer do broto de uma planta, dentre outros ensinamentos deixados pelo projeto, realizado na

Escola Normal Superior.

\section{AGRADECIMENTOS}

Aos acadêmicos do Curso de Pedagogia, pela parceria firmada durante a execução de todo trabalho na disciplina de Educação Ambiental, ao docente da turma pelo espaço proporcionado para a pesquisa. Nosso muito obrigado:

A CAPES e FAPEAM, pelas bolsas de fomento concedidas.

A Danny Neisel Lima Gutarra, pela tradução do resumo ao Inglês.

A Carmem Lúcia Moura Machado, pela revisão ortográfica.

\section{REFERÊNCIAS}

ALENCAR, L. D.; BARBOSA M. F. N. Educação Ambiental no Ensino Superior: ditames da Política Nacional de Educação Ambiental. Revista Direito Ambiental e sociedade. v.8. n.2. p. 229-255,2018.

ALVES, D. Sensopercepção em ações de educação ambiental. Brasília. Ministério da Educação e do Desporto - MEC. Instituto Nacional de Estudos e Pesquisas Educacionais. Série documental: Antecipações, n.7. out. 1995.

BARDIN, L. Análise de conteúdo. São Paulo: Edições 70, 2016.

BAUER, M. W.; AARTS, B. A construção do corpus: um princípio para a coleta de dados qualitativos. In: BAUER, M. W; GEORGE, G. (orgs.). Pesquisa Qualitativa com texto, imagem e som: um manual prático. 2 ed. Petrópolis: Vozes, 2015.

BRASIL. Constituição Federal. Artigo 225. Inciso VI. Brasília: 1988.

BRASIL. Lei no 9795, de 27 de abril de 1999. Política Nacional de Educação Ambiental.

BRASIL. Decreto $\mathbf{n}^{\mathbf{0}}$ 4.281, de 25 de junho de 2002, que instituiu a Política Nacional de Educação Ambiental.

BRASIL. Resolução CNE/CP no 2, de junho de 2012. Estabelece as Diretrizes Curriculares Nacionais para a Educação Ambiental. Disponível em: http://portal.mec.gov.br/index.php?option=com_content\&view=article\&id=18695\&Itemid=8 66. Acesso em: 22 set. 2019. 
COSTA, C. A.; COSTA, F. G. A Educação como instrumento na construção da consciência ambiental. Nucleus, v.8, n.2, out.2011.

FREITAS, D.; OLIVEIRA, H. T.; ZUIN, V. G. Metodologia de projetos na formação inicial de professoras/es: contributos para a aprendizagem de conhecimentos e habilidades requeridas na atuação de educadoras/es comprometidas/os com as questões ambientais. In: $\mathbf{V}$ Congresso Internacional de Educação Superior. Universidade Havana, 2006. Disponível em: www.ufscar.br/ ciecultura/denise/evento_1.pdf. Acesso em: 14 out. 2018.

MANZANO, M. A. A temática ambiental nas séries iniciais do Ensino Fundamental: concepções reveladas no discurso de professoras sobre sua prática. Dissertação (Mestrado em Educação para a Ciência) - Faculdade de Ciências - Universidade Estadual Paulista "Júlio de Mesquita $\quad 2003 . \quad$ Dilho”, 2 em: https://www2.fc.unesp.br/BibliotecaVirtual/DetalhaDocumentoAction.do?idDocumento=43. Acesso em: 01 ago. 2018.

MATURANA, H. Educação e linguagem na educação e na política. Belo Horizonte, UFMG, 1998.

MINAYO, M. C. S. (Org.) Pesquisa social: teoria, método e criatividade. 22 ed. Petrópolis, RJ: Vozes, 2003.

PERES, M. C. L.; BENATI, K. R.; SILVA, P. M. S.; AMORIM, V. E.P.; DIAS. M. A. Sensibilização de alunos do ensino fundamental a partir de práticas ambientais no Parque Metropolitano de Pituaçu. In: Revista monografias ambientais - REMOA. Santa Maria, v.17, e 11, p. 1-8, 2018. Disponível em: https://periodicos.ufsm.br/remoa/article/view/34625/pdf. Acesso: 06 dez. 2019.

SILVA, F. S.; SANTOS, S. D. F.; FACHÍN-TERÁN, A. O Jardim zoológico do CIGS: um espaço estratégico para despertar a sensibilização ambiental. Revista REAMEC, Cuiabá - MT, v. 7, n. 2, jul/dez 2019.

THOMAZ, C. E. Educação ambiental na formação inicial de professores. Dissertação (Mestrado em educação) - Programa de Pós-Graduação em Educação - Pontífica Universidade Católica de Campinas. Campinas, 2006.

TRISTÃO, M. A educação ambiental na formação de professores: redes de saberes. 2 ed. São Paulo: Annablume; Vitória: Facitec, 2008. 
Submetido em: 15 de março de 2020.

Aprovado em: 24 de maio de 2020. 